Pesq. Vet. Bras. 37(4):359-367, abril 2017 DOI: $10.1590 / \mathrm{S} 0100-736 \mathrm{X} 2017000400010$

\title{
Comparação de duas classificações histopatológicas com o padrão de imuno-marcação para KIT, a avaliação da proliferação celular e com a presença de mutações no $c$-KIT de mastocitomas cutâneos caninos ${ }^{1}$
}

\author{
Anna Paula M. Carvalho ${ }^{2 *}$, Eulógio C.Q. Carvalho ${ }^{2}$, Andrigo B. De Nardi ${ }^{3}$ \\ e Leonardo S. Silveira ${ }^{2}$
}

\begin{abstract}
Carvalho A.P.M., Carvalho E.C.Q., De Nardi A.B. \& Silveira L.S. 2017. [Comparison of two histopathological classifications with pattern of immunostaining KIT, evaluation of cell proliferation and the presence of mutations in c-KIT canine cutaneous mast cell tumors.] Comparação de duas classificações histopatológicas com o padrão de imuno-marcação para KIT, a avaliação da proliferação celular e com a presença de mutações no c-KIT de mastocitomas cutâneos caninos. Pesquisa Veterinária Brasileira 37(4):359-367. Laboratório de Morfologia e Patologia Animal, Centro de Ciências e Tecnologias Agropecuárias, Universidade Estadual do Norte Fluminense Darcy Ribeiro, Campos dos Goytacazes, RJ 28013-602, Brazil. E-mail: annapmcarvalho@gmail.com

Histopathological classification is the method of choice to predict the biological behavior of mast cell tumor. Currently, the methods of Patnaik and Kiupel are used to divide them into degrees of malignancy. The objective of this study was to compare the two histological grades with clinical, immunohistochemical markers and the presence of mutations to evaluate the characteristics that are more related to each other and with the worst prognosis. Sixty-one dogs were evaluated, taking into account sex, race, age, tumor location, tumor grade by grades Patnaik and Kiupel, infiltration of eosinophils, pattern KIT, Ki-67 and the presence of mutation. The variables were correlated using the chi-square test, Fisher's exact test, verisimilitude test and relative risk test. The older dogas were the most affected, while animals mixed breed, Boxer breeds, Labrador and Pinscher were those with greater predisposition to tumor development. The tumor location and age are associated with tumor grade. The tumors in the head, neck and genital area are 10 times more likely to be classified as high-grade ( $R R=10,667 ; 95 \%$ CI 1.909 to $59.615, p=0.004$ ) grau and old-aged eight times more likely ( $R R=8.00,95 \%$ CI 0.955 to $67.009, p=0.029$ ). The grade II tumors and the low degree were the most frequent and the two histological scores showed very significant correlation $(p<0.001)$. The concentration of eosinophilic infiltration showed no significant correlation with any of the histological scores. The standard KIT was dependent on tumor location ( $\mathrm{p}=0.015)$, genital tumors, head and neck had 18 times more likely to have cytoplasmic pattern ( $\mathrm{RR}=18.571,95 \%$ CI 1.954 to 176.490 , $\mathrm{p}=0.003)$, and Patnaik $(\mathrm{p}=0.001)$ and Kiupel $(\mathrm{p}<0.001)$ ratings. The high grade tumors are 36 times more likely to have cytoplasmic pattern (RR 36.00, 95\% CI 4.35-297.948 $\mathrm{p}<0.001)$. The marking of the Ki-67 showed a dependence on the location $(\mathrm{p}=0.024)$. The presence of mutation in exon 11 of the juxtamembrane domain showed no association with any of the clinical variables of the histological scores, the concentration of eosinophils and KIT standard. The presence of the mutation was significantly correlated only
\end{abstract}

\footnotetext{
${ }^{1}$ Recebido em 26 de fevereiro de 2016.

Aceito para publicação em 16 de junho de 2016.

${ }^{2}$ Laboratório de Morfologia e Patologia Animal, Centro de Ciências e Tecnologias Agropecuárias, Universidade Estadual do Norte Fluminense Darcy Ribeiro (UENF), Av. Alberto Lamego, 2000 - Parque California, Cam-
}

pos dos Goytacazes, RJ 28013-602, Brasil. *Autor para correspondência: annapmcarvalho@gmail.com

${ }^{3}$ Departamento de Clínica e Cirurgia Veterinária, Faculdade de Ciências Agrárias e Veterinárias, Universidade Estadual Paulista Júlio de Mesquita Filho (Unesp), Campus de Jaboticabal, SP 14884-900, Brasil. 
to the Ki-67 $(\mathrm{p}=0,010)$. The results suggest that the location is the clinical variable most related to prognosis and that only Kiupel classification associated with immunohistochemistry are efficient to assess tumor behavior.

INDEX TERMS: Canine cutaneous mast cell tumors, immunohistochemistry, KIT, Ki-67, mutation.

RESUMO.- A graduação histopatológica é o método de eleição para prever o comportamento biológico do mastocitoma e, atualmente, são utilizados os métodos de Patnaik e de Kiupel para dividi-los em graus de malignidade. 0 objetivo do presente trabalho foi comparar as duas classificações histológicas com as variáveis clínicas, os marcadores imuno-histoquímicos e com a presença de mutações para verificar as características que estão mais relacionadas entre si e com os piores prognósticos. Foram avaliados 61 animais, levando em consideração o sexo, a raça, a idade, a localização tumoral, o grau tumoral pelas classificações de Patnaik e Kiupel, a infiltração de eosinófilos, a marcação do KIT e do Ki-67 e a presença de mutação. As variáveis foram correlacionadas utilizando os testes de qui-quadrado, teste de Fisher, teste de verossimilhança e o teste de risco relativo. Os animais idosos foram os mais acometidos, enquanto os animais sem raça definida e os das raças Boxer, Labrador e Pinscher foram aqueles com maior predisposição ao desenvolvimento tumoral. A localização e a idade estão associadas ao grau tumoral. Os tumores em cabeça, pescoço e região genital têm 10 vezes mais chance de serem classificados como de alto grau (RR=10,667; IC95\% 1,909-59,615, $\mathrm{p}=0,004)$ e os idosos oito vezes mais chance $(\mathrm{RR}=8,00$; IC95\% 0,955-67,009; $p=0,029)$. Os tumores de grau II e os de baixo grau foram os mais encontrados e as duas classificações histológicas demonstram correlação muito significativa entre si $(p<0,001)$. A concentração do infiltrado eosinofílico não demonstrou correlação significativa com nenhuma das classificações histológicas. 0 padrão KIT foi dependente da localização tumoral $(p=0,015)$, já que os tumores genitais, na cabeça e no pescoço possuíam 18 vezes mais chance de apresentarem padrão citoplasmático ( $R R=18,571$; IC95\% 1,954-176,490; $p=0,003)$, e das classificações de Patnaik $(p=0,001)$ e Kiupel $(p<0,001)$, sendo que os tumores de alto grau têm 36 vezes mais chance de apresentarem padrão citoplasmático (RR=36,00, IC95\% 4,35-297,948; $p<0,001)$. A marcação do Ki-67 demonstrou dependência da localização $(p=0,024)$. A presença de mutação no exon 11 do domínio justamembrana não demonstrou associação com nenhuma das variáveis clínicas, das classificações histológicas, da concentração de eosinófilos e do padrão KIT. A presença da mutação foi correlacionada significativamente apenas ao Ki-67 $(\mathrm{p}=0,010)$. Os resultados obtidos sugerem que a localização é a variável clínica mais relacionada ao prognóstico e que apenas a classificação de Kiupel associada à imuno-histoquímica são eficientes para avaliar o comportamento tumoral.

TERMOS DE INDEXAÇÃO: Mastocitomas cutâneos caninos, imuno-histoquímica, KIT, Ki-67, mutação.

\section{INTRODUÇÃO}

O mastocitoma é o tumor cutâneo mais comum em cães (London \& Séguin 2003, Withrow \& Vail 2007), representando 16 a $21 \%$ dos tumores caninos (Daleck et al. 2008). Aco- mete, principalmente, cães entre oito e nove anos (London \& Séguin 2003) e não há predileção por sexo (Costa-Casagrande et al. 2008, Furlani et al. 2008). Há predisposição racial do Boxer (Costa-Casagrande et al. 2008, Furlani et al. 2008), Boston Terrier, Bulldog inglês (Crow 1977, Goldschmidt \& Hendrick 2002, London \& Séguin 2003), Labrador, Golden Retrievers, Cocker Spaniel, Schnauzer, Teckel e Shar-pei (Daleck et al. 2008). Cães mestiços também possuem alta incidência (Costa-Casagrande et al. 2008, Furlani et al. 2008).

0 mastocitoma cutâneo se localiza, frequentemente, nas regiões do tronco e regiões perineal e genital (50-60\% dos casos) (Furlani et al 2008), seguida dos membros (25\%) (Govier 2003), mas também podem aparecer com certa frequência na cabeça e no pescoço (Kiupel et al 2005, Fulcher et al 2006).

A graduação histopatológica é o método de eleição para prever o comportamento biológico do mastocitoma (Patnaik et al. 1984). Atualmente, são usadas duas classificações. Na de Patnaik et al. (1984), o mastocitoma é classificado em três graus de malignidade e na proposta por Kiupel et al. (2011) que os tumores são divididos em dois graus de malignidade. A principal desvantagem da classificação histológica de Patnaik é a grande predominância de tumores de grau II (intermediário) e a grande variação entre observadores, o que estimulou o desenvolvimento de uma nova forma de classificar os mastocitomas (Kiupel et al. 2011).

$\mathrm{Na}$ imuno-histoquímica, há diversos anticorpos à disposição para utilização nos mastocitomas que auxiliam no diagnóstico e na determinação do prognóstico (Oliveira 2008). A proteína Ki-67 tem seu índice aumentado de acordo com grau histológico do tumor e está associado à recidiva e à mortalidade associada ao mastocitoma (Webster et al. 2007).

0 receptor KIT é uma proteína transmembrana. Em cães, mastócitos normais demonstram o KIT apenas na membrana, enquanto que os mastocitomas indiferenciados tendem a expressar o KIT citoplasmático (London et al. 1996, Reguera et al. 2000, Morini et al. 2004, Kiupel et al. 2004).

Muitos estudos têm demonstrado uma proporção significativa de cães com mastocitoma apresentando alguma mutação no proto-oncogenes c-KIT. Esta característica é mais comum em tumores indiferenciados e em prognósticos ruins (Withrow \& Vail 2007). Na maioria das vezes, a mutação consiste em uma duplicação em tandem no domínio justamembrana, codificada pelos exon 11-12 e responsável pela regulação negativa da ativação do receptor, o que resulta em estímulo persistente para a multiplicação celular (London et al. 1999, London 2009).

0 objetivo do presente trabalho foi comparar as duas classificações histológicas com as variáveis clínicas, os marcadores imuno-histoquímicos e com a presença de mutações para verificar as características que estão mais relacionadas entre si e com os piores prognósticos. 


\section{MATERIAL E MÉTODOS}

Foram utilizados 61 tumores de cães (Canis familiaris), independente de raça, idade e sexo, provenientes de material de arquivo da Universidade Estadual do Norte Fluminense Darcy Ribeiro em Campos dos Goytacazes/RJ, com diagnóstico prévio de mastocitoma cutâneo. 0 material utilizado eram peças cirúrgicas que foram coletadas entre 2011 e 2014.

A idade, o sexo, a raça e a localização foram analisados para verificar se esses fatores estão relacionados a outras variáveis associadas à piores prognósticos.

A localização tumoral foi dividida em cabeça, pescoço, dorso, ventre, membro, genital, disseminado e de localização desconhecida quando esta não estava descrita. Nos casos em que o animal possuía mais de um tumor, foi classificado como disseminado e usado aquele que apresentava pior grau na classificação histopatológica. Os tumores nas regiões do prepúcio, da bolsa escrotal ou da vulva foram agrupados em uma mesma categoria e considerados como de localização genital.

Os animais foram divididos em cinco classes etárias (0-3 anos, 4-6 anos, 7-9 anos, 10-12 anos e maiores que 12 anos).

0 exame histopatológico foi realizado objetivando a confirmação do diagnóstico e a diferenciação dos mastocitomas em graus pela classificação de Patnaik, Ehler \& MacEwen, (1984) (I, II e III) e de Kiupel et al. (2011) (alto e baixo). 0 material foi reemblocado e as lâminas foram analisadas em microscópio óptico por três patologistas diferentes. Os exames foram realizados às cegas e, após a observação individual, os diagnósticos foram confrontados e, quando necessário, os patologistas chegaram a um consenso quanto à classificação e a diferenciação em graus dos mastocitomas. Além das características histológicas utilizadas para a classificação em graus, foi verificada a presença de infiltrado eosinofílico.

0 infiltrado eosinofílico foi classificado baseado no modelo adotado por Oliveira (2008), a partir da média de células contadas em cinco campos de maior aumento (400x). A concentração de eosinófilo foi dividida em grupos. Os eosinófilos eram classificados como ausentes, quando não eram visualizados; o infiltrado foi considerado leve, quando o tumor possuía poucos eosinófilos por campo (menos de 50 eosinófilos por campo); o infiltrado foi considerado como moderado, quando o tumor apresentava uma concentração média de eosinófilos (50-100 por campo); e quando o tumor possuía uma alta concentração de eosinófilos por campo, chamando mais atenção que o próprio tumor, a concentração foi considerada intensa (mais de 100 por campo).

Foram utilizados os anticorpos primários anti Ki-67, clone MIB-1 (anticorpo monoclonal, anti Ki67 humano, DakoCytomation) para avaliar o Ki-67 e CD117 (anticorpo policlonal, anti $c$ -KIT humano, DakoCytomation) para avaliar a oncoproteína KIT. A diluição do CD117 foi feita 1:1250 e a do MIB-1 foi de 1:100.

Para a avaliação do Ki-67, foi utilizada a metodologia baseada em Webster et al. 2007, que conta os tumores com marcação positiva para Ki67 (média de mais de 23 células marcadas). Os tumores com marcação maior que 23 foram descritos como tumores proliferativos e os que possuíam marcação negativa foram descritos como não-proliferativos. 0 controle positivo foi feito com a utilização de mastocitomas que já haviam sido marcados anteriormente e havia controle interno na mesma lâmina, só sendo considerados para a avaliação dos resultados aqueles que também possuíam a camada basal marcada com o anticorpo.

Segundo Webster et al. (2004), a marcação do anticorpo CD117 pode apresentar três padrões KIT: perimembranoso, quando há marcação membranar; citoplasmático focal, quando há marcação citoplasmática paranuclear; e citoplasmático difuso, quando há marcação citoplasmática intensa.
A observação das lâminas foi realizada em microscópio óptico nas objetivas de 10x, 20x e 40x para a observação das marcações dos anticorpos.

A Reação em Cadeia de Polimerase (PCR) foi realizada para verificar a presença de mutação no proto-oncogene $c$-KIT, com a utilização de um protocolo adaptado da técnica de Webster et al. (2006a), no Progenbio. A PCR foi realizada em 40 blocos de parafina mais recentes (2013-2014) e nos quais a presença de material genético disponível permitiria a realização do exame, destes 33 eram de animais diferentes e sete pertenciam a animais com tumores disseminados.

Depois de confirmado o tumor, um pequeno fragmento com cerca de $2 \mathrm{~mm}$ foi seccionada de cada bloco de parafina para a extração do DNA. Seguindo o protocolo de Zemke et al. (2002), a parafina foi retirada ao colocar uma amostra do tecido em $400 \mu \mathrm{L}$ da solução TRIS com EDTA para a digestão. A amostra foi colocada a $95^{\circ} \mathrm{C}$ por 10 minutos e aquecida duas vezes por 30 segundos em forno micro-ondas na potência máxima, com homogeneização completa após cada aquecimento.

Foi adicionada $5 \mu \mathrm{l}$ de $15 \mathrm{mg}$ de proteinase $\mathrm{K}$ em cada uma das amostras e estas foram incubadas a $42^{\circ} \mathrm{C}$ "overnight" ou até que o fragmento tecidual fosse completamente digerido. A proteinase $\mathrm{K}$ foi inativada por calor a $95^{\circ} \mathrm{C}$ por 10 minutos e as amostras centrifugadas a 12.000 RPM em uma microcentrífuga por 10 minutos e transferida para outro túbulo, sem a parafina. Em torno de 200 $\mu \mathrm{l}$ de cada reação foi usada para a PCR.

A amplificação do DNA da região justamembrana de $c$-KIT foi realizada pelos primers ATCTGTCTCTCTTTTCTCCCCC e TGGGGTTCCCTAAAGTCATTGT (desenho realizado no Prmer -Blast ${ }^{\circledR}$ ), baseados no exon 11 pela técnica de PCR convencional. 0 material passou por uma desnaturação inicial que durou quatro minutos a $94^{\circ} \mathrm{C}$, seguido de 35 ciclos de 1 minuto por $94^{\circ} \mathrm{C}$, mais 35 ciclos de dois minutos a $66^{\circ} \mathrm{C}, 35$ ciclos de três minutos a $72^{\circ} \mathrm{C} \mathrm{e}$ uma fase final de oito minutos por $72^{\circ} \mathrm{C}$. 0 produto da amplificação foi colocado em gel de agarose a 4\%, corados com brometo de etídio e visualizados com luz ultravioleta para avaliação por Eletroforese. Em cada gel analisado, foi utilizado um controle positivo e um negativo para permitir a avaliação adequada das bandas formadas.

Na análise estatística, foram avaliadas variáveis contínuas e categóricas. As variáveis contínuas foram a idade e o número de células marcadas com anticorpo anti Ki-67. As variáveis categóricas analisadas foram o sexo, a idade, a raça, a localização, o grau histológico (nas duas classificações), a concentração de eosinófilos, a marcação do KIT e a presença de mutação.

Os resultados das análises histopatológicas foram analisados estatisticamente pelo programa IBM SPSS Statistics 20. Foi feita a estatística descritiva com as variáveis contínuas, calculando a média, o mínimo, o máximo e o desvio padrão. Com as variáveis categóricas foi calculada a frequência e a porcentagem de cada uma delas.

Foram realizados testes para correlacionar as diversas variáveis entre si. Para verificar a dependência entre as variáveis, foram usados os testes de qui-quadrado $\left(\chi^{2}\right)$, o teste da razão de verossimilhança e o teste exacto de Fisher e realizado o teste de risco relativo quando necessário.

\section{Demográficos}

\section{RESULTADOS}

O sexo foi informado para 61 animais. Desses, 36 (59\%) eram machos e 25 (41\%) eram fêmeas. A idade dos animais variou entre 2 e 18 anos, com média de 9,1 $\pm 3,28$ anos. A idade em que ocorre o diagnóstico dos tumores foi independente do sexo $\left(\chi^{2}=3,49, g l=4, p=0,479\right)$. 
Em relação à raça, os cães sem raça definida (SRD) foram os mais representados $(15[24,6 \%])$, seguidos do Boxer (14[23\%]). Foram avaliados sete animais da raça Labrador e Pinscher (11,5\% cada). As outras raças relatadas no estudo foram Fox Paulistinha, Pit Bull, Golden Retriever, Bichon Frisé, Bernesse, Maltês, Dachshund, Rottweiler, Akita, Pastor Alemão e Pug, totalizando 15 raças. Nenhuma raça teve dependência da idade $\left(\chi^{2}=64,202, \mathrm{gl} .=56, \mathrm{p}=0,211\right)$ ou do sexo $\left(\chi^{2}=21,556, \mathrm{gl} .=14, \mathrm{p}=0,088\right)$ para o aparecimento do tumor.

Cinquenta e dois tumores tinham localização conhecida, sendo o membro a mais frequente $(20[38,5 \%])$. A segunda localização mais comum foi a região genital $(8[15,4 \%])$, seguida das regiões ventral e dorsal e dos tumores disseminados $(7[13 \%])$. Também foram encontrados tumores nas regiões da cabeça e do pescoço. No total foram achados sete localizações tumorais diferentes. Nenhuma das variáveis clínicas, como a raça $\left(\chi^{2}=65,937, \mathrm{gl} .=78, \mathrm{p}=0,833\right)$, a idade $\left(\chi^{2}=22,278, g l .=24, p=0,563\right)$ e o sexo $\left(\chi^{2}=10,496\right.$, gl. $=7$, $\mathrm{p}=0,109)$ estão correlacionadas estatisticamente com a localização tumoral.

\section{Grau histológico}

A avaliação histopatológica foi realizada em 61 animais. Pela classificação Patnaik et al. (1984), dos 61 tumores, seis $(9,8 \%)$ foram considerados Grau I, 45 (73,8\%) Grau II e 10 $(16,4 \%)$ Grau III. A determinação em graus dos tumores por esta classificação foi independente do sexo $\left(\chi^{2}=0,181\right.$, gl. $=2 \mathrm{p}=0,913)$, da raça $\left(\chi^{2}=19,828\right.$, gl. $\left.=28, \mathrm{p}=0,871\right)$, da idade $\left(\chi^{2}=15,348\right.$, gl. $\left.=8, p=0,053\right)$ e da localização $\left(\chi^{2}=7,565\right.$, $\mathrm{gl} .=12, \mathrm{p}=0,818)$.

Pela classificação de Kiupel et al. (2011), dos 61 tumores analisados, 42 (68,85\%) foram classificados como baixo grau e 19 (31,15\%) como alto grau. A determinação em graus pela classificação de Kiupel et al. (2011) demonstrou independência do sexo $\left(\chi^{2}=2,45, \mathrm{gl} .=1 \mathrm{p}=0,117\right)$ e da raça $\left(\chi^{2}=15,299\right.$, gl. $=14, p=0,358)$, mas dependência da idade $\left(\chi^{2}=13,041\right.$, gl. $=4, p=0,011)$ e da localização $\left(\chi^{2}=13,733, g l .=6, p=0,033\right)$. 0 risco relativo demonstrou que os tumores com localização genital, cabeça ou pescoço tem 10 vezes mais chances de ser classificado com alto grau do que os de membros ( $R R=10,667$, IC95\% 1,909-59,615, $\mathrm{p}=0,004)$ e que os idosos tem oito vezes mais chance de ter um tumor de alto grau do que os animais jovens (RR=8,00, IC95\% 0,955-67,009, $p=0,029$ ).

Dos seis tumores classificados como grau I, todos foram classificados como baixo grau. Dos 45 tumores como grau
II, $34(75,5 \%)$ foram classificados como baixo grau e 11 $(24,5 \%)$ como alto grau. Já os classificados como grau III, dois foram classificados como baixo grau e oito como alto grau. As duas classificações demonstraram dependência uma da outra $\left(\chi^{2}=15,612\right.$, gl. $=2$, $\left.p<0,001\right)$.

Foram encontrados tumores indiferenciados com a presença de infiltrado eosinofílico intenso, mas este também foi encontrado em tumores bem diferenciados e pouco agressivos.

Dos 61 mastocitomas avaliados, o infiltrado de eosinófilos esteve ausente em seis (9,8\%), infiltração leve em 15 $(24,6 \%)$, moderado em 25 (41\%) e intenso em 15 (24,6\%). A concentração eosinofílica foi independente das variáveis clínicas sexo $\left(\chi^{2}=4,42, \mathrm{gl} .=3, \mathrm{p}=0,220\right)$, idade $\left(\chi^{2}=12,265\right.$, $\mathrm{gl} .=12, \mathrm{p}=0,425)$, raça $\left(\chi^{2}=45,428, \mathrm{gl}=42 \mathrm{p}=0,338\right)$ e localização $\left(\chi^{2}=22,833, g l .=18, p=0,197\right)$. A concentração também foi independente das classificações de Patnaik $\left(\chi^{2}=3,025\right.$, $\mathrm{gl} .=6, \mathrm{p}=0,806)$ e Kiupel $\left(\chi^{2}=4,21, \mathrm{gl} .=3, \mathrm{p}=0,240\right)$.

\section{Avaliação imuno-histoquímica}

Dos 61 tumores em que o KIT foi avaliado, 29 (47,54\%) apresentaram padrão perimembranoso, $14(22,95 \%)$ padrão citoplasmático focal e 18 (29,51\%) padrão citoplasmático difuso (Fig.1).

Ao correlacionar às variáveis clínicas, o padrão KIT de marcação foi independente do sexo $\left(\chi^{2}=0,911\right.$, gl. $=2$, $\mathrm{p}=0,634)$, da idade $\left(\chi^{2}=9,644, \mathrm{gl}=8, \mathrm{p}=0,291\right)$ e da raça $\left(\chi^{2}=\right.$ $31,639, \mathrm{gl} .=28, \mathrm{p}=0,289)$, mas dependente da localização $\left(\chi^{2}=24,982\right.$, gl. $\left.=12, p=0,015\right)$ (Quadro 1). 0 risco relativo demonstrou que os tumores em localização genital, cabeça ou pescoço tem 18 vezes mais chances de ser classificado como padrão citoplasmático do que os de membros $(R R=18,571$, IC95\% 1,954-176,490, p=0,003). Dos 29 tumores com padrão perimembranoso, cinco $(17,24 \%)$ eram de grau I e 24 $(82,76 \%)$ de grau II. Nenhum tumor com padrão perimembranoso foi classificado como grau III. Já na classificação de Kiupel et al. (2011), dos 29 tumores perimembranosos, 28 $(96,5 \%)$ eram de baixo grau e um $(3,5 \%)$ de alto grau.

Dos tumores com padrão citoplasmático focal, um $(7,14 \%)$ era de grau I, $10(71,43 \%)$ de grau II e $3(21,43 \%)$ de grau III. Pela classificação de Kiupel et al (2011), dos 14 citoplasmáticos focais, oito $(57,14 \%)$ eram de baixo grau e $6(42,86 \%)$ de alto grau.

Os tumores citoplasmáticos difusos eram 11 (61,11\%) de grau II e sete $(38,89 \%)$ de grau III. Nenhum desses tu-

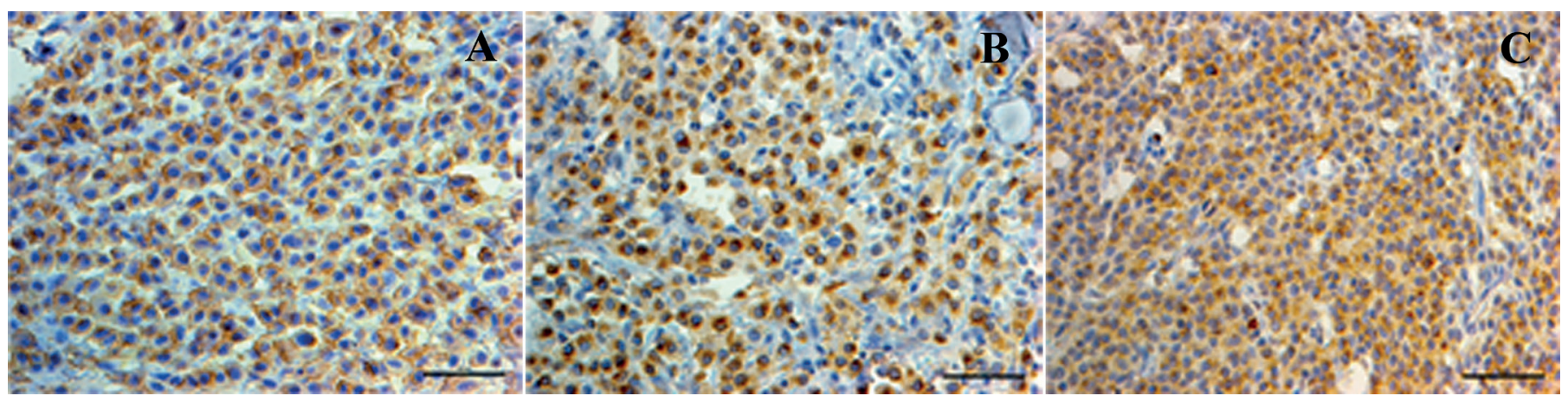

Fig.1. Padrão de marcação do KIT em mastocitoma de cão. (A) Padrão perimembranoso; (B) Padrão citoplasmático focal; (C) Padrão citoplasmático difuso. 
Quadro 1. Distribuição da classificação de KIT de acordo com a localização tumoral

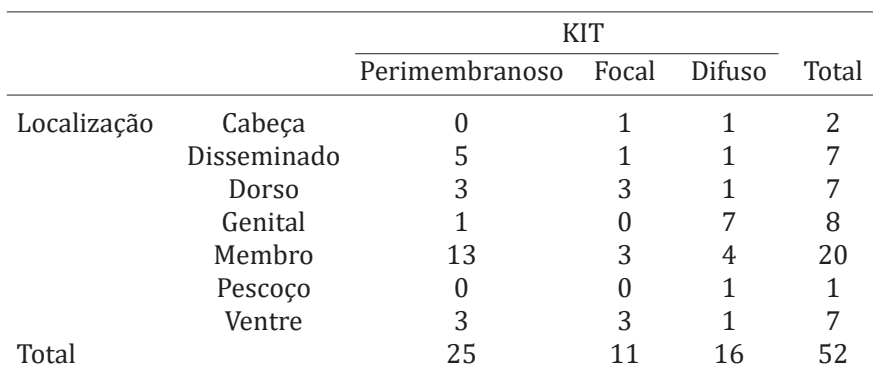

$\chi^{2}=24,982, \mathrm{gl} .=12, \mathrm{p}=0,015 . \mathrm{RR}=18,571, \mathrm{IC} 95 \%$ 1,954-176,490, $\mathrm{p}=0,003$.

\section{Quadro 2. Distribuição da marcação de KIT de acordo com classificação histológica de Patnaik, Ehler \& MacEwen} (1984)

\begin{tabular}{lccccc}
\hline & & \multicolumn{3}{c}{ KIT } & \\
\cline { 3 - 5 } & & Perimembranoso & Focal & Difuso & Total \\
\hline \multirow{2}{*}{ Patnaik } & I & 5 & 1 & 0 & 6 \\
& II & 24 & 10 & 11 & 45 \\
& III & 0 & 3 & 7 & 10 \\
Total & & 29 & 14 & 18 & 61
\end{tabular}

$\overline{\chi^{2}=19,405, \text { gl. }=4}, \mathrm{p}=0,001$.

Quadro 3. Distribuição da marcação de KIT de acordo com classificação histológica de Kiupel et al. (2011)

\begin{tabular}{lccccc}
\hline & & \multicolumn{3}{c}{ KIT } & \\
\cline { 3 - 5 } & & Perimembranoso & Focal & Difuso & Total \\
\hline \multirow{2}{*}{ Kiupel } & Alto & 1 & 6 & 12 & 19 \\
& Baixo & 28 & 8 & 6 & 42 \\
Total & & 29 & 14 & 18 & 61
\end{tabular}

$\chi^{2}=21,859$, gl. $=2, p<0,001 . R R=36,00$, IC95\% 4,35-297,948, $p<0,001$.

mores foi classificado como de grau I pela classificação de Patnaik, Ehler \& MacEwen (1984). Na classificação de Kiupel et al. (2011), seis (33,33\%) eram de baixo grau e 12 $(66,67 \%)$ de alto grau.

Ao correlacionar a imuno-histoquímica à classificação histológica, verificou-se que o padrão KIT de marcação é dependente da classificação de Patnaik et al. (1984) $\left(\chi^{2}=19,405\right.$, gl. $\left.=4, p=0,001\right)$ (Quadro 2) e da classificação de Kiupel et al. (2011) $\left(\chi^{2}=21,859\right.$, gl. $\left.=2, p<0,001\right)$ (Quadro 3). 0 risco relativo demonstrou que os tumores em de alto grau tem 36 vezes mais chances de ser classificado com marcação citoplasmática do que os de baixo grau (RR=36,00, IC95\% 4,35-297,948, $\mathrm{p}<0,001$ ).

0 Ki-67 necessita da presença da proteína para interagir com o anticorpo, como o material era de arquivo e a fixação prolongada pode mascarar a presença da proteína, a marcação do Ki-67 só foi eficiente em 26 tumores. Destes, $17(65,38 \%)$ eram não proliferativos e nove $(34,62 \%)$ eram proliferativos. A quantidade de células marcadas variou de zero até 100 por campo com a utilização da gradícula. A média de marcação celular foi $14 \pm 20,71$.

A imuno-histoquímica com Ki-67 é independente do sexo $\left(\chi^{2}=0,460\right.$, gl. $\left.=1, p=0,683\right)$, da raça $\left(\chi^{2}=6,531, \mathrm{gl} .=66\right.$, $\mathrm{p}=0,366)$ e da idade $\left(\chi^{2}=1,924, \mathrm{gl} .=3, \mathrm{p}=0,588\right)$, mas é dependente da localização $\left(\chi^{2}=12,885, \mathrm{gl} .=5, \mathrm{p}=0,024\right)$.
Usando a classificação de Patnaiketal. (1984), os tumores não proliferativos eram dois $(11,8 \%)$ de grau I, 10 (58,8\%) de grau II e cinco (29.4\%) de grau III. Já os tumores proliferativos eram seis de grau II $(66,67 \%)$ e três $(33,33 \%)$ de grau III. Nenhum dos tumores proliferativos teve classificação de grau I. Pela classificação de Kiupel et al (2011), os tumores não proliferativos eram $12(70,59 \%)$ de baixo grau e cinco $(29,41 \%)$ de alto grau. Os tumores proliferativos eram três $(66,67 \%)$ de baixo grau e seis $(66,67 \%)$ de alto grau.

A marcação com o anticorpo anti Ki-67 não demonstrou correlação significativa com nenhuma das classificações histológicas. Ela foi independente da classificação de Patnaik et al. $\left(\chi^{2}=1,787\right.$, gl. $\left.=2, p=0,409\right)$ e da classificação de Kiupel $\left(\chi^{2}=3,371, \mathrm{gl} .=1, \mathrm{p}=0,066\right)$.

Comparando as duas análises imuno-histoquímicas, oito $(47,06 \%)$ tumores não proliferativos eram do tipo perimembranoso, cinco $(29,41 \%)$ citoplasmáticos focais e quatro $(23.53 \%)$ citoplasmáticos difusos. Já os proliferativos, um $(11,11 \%)$ era do tipo perimembranoso, três $(33,33 \%)$ eram citoplasmáticos focais e cinco $(55,56 \%)$ eram citoplasmáticos difusos. As marcações para KIT e Ki67 são independentes entre si $\left(\chi^{2}=4,312\right.$, gl. $\left.=2, p=0,116\right)$.

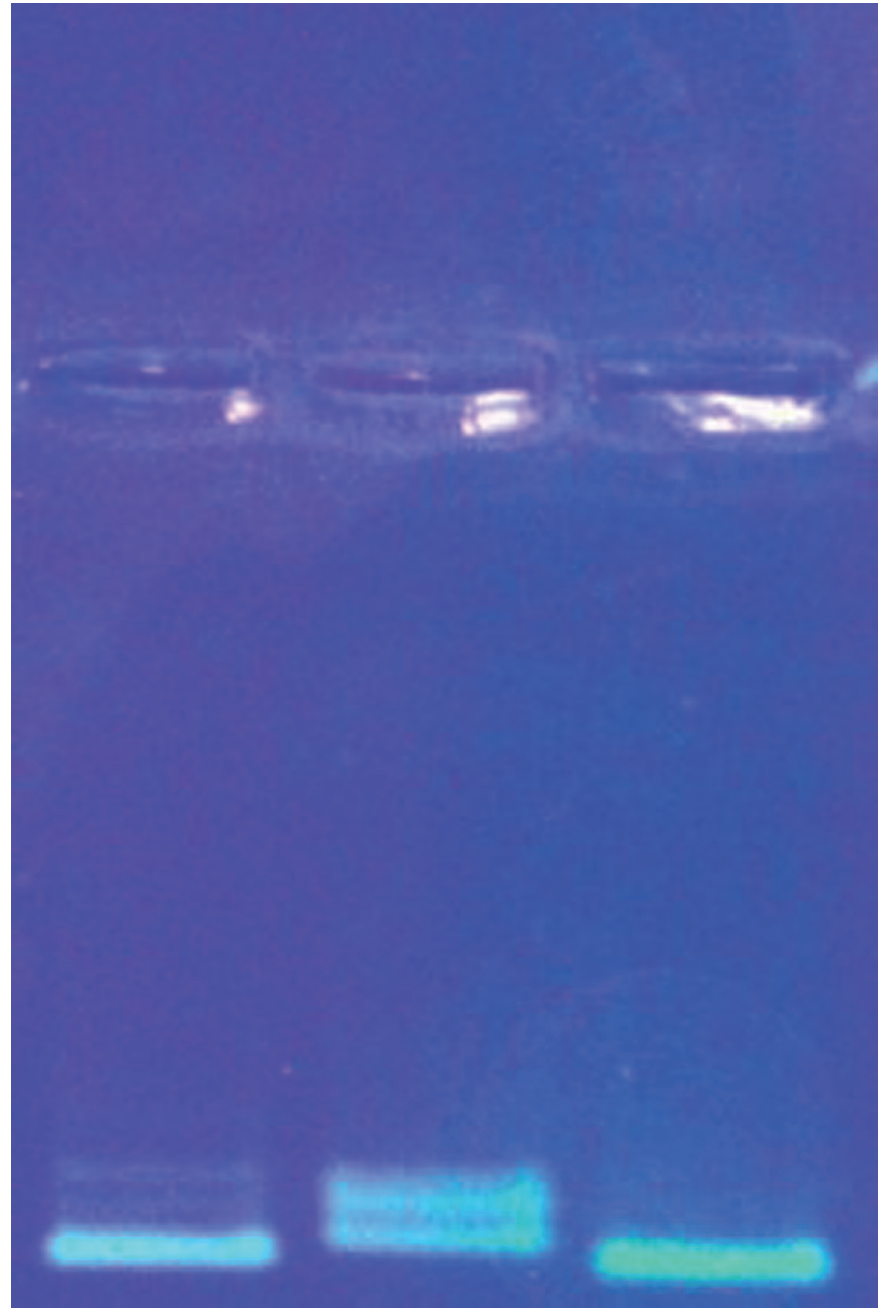

Fig.2. Gel de marcação da PCR com a presença de mutação. Da esquerda para a direita: controle da presença de mutação no exon 11, um caso de mutação de duplicação no exon 11 e um caso normal. 
A concentração de eosinófilo demonstrou independência do padrão KIT $\left(\chi^{2}=6,997\right.$, gl. $\left.=6, p=0,321\right)$, mas dependência do Ki-67 ( $\chi^{2}=9,062$, gl. $\left.=3, p=0,028\right)$.

\section{Mutação do $c$-KIT}

Dos 40 tumores analisados, em um houve reação inespecífica, sobrando 32 indivíduos diferentes, com 39 tumores analisados. Apenas três tumores apresentaram mutação e elas eram duplicações em tandem no exon 11 do domínio justamembrana, o que representa $7,7 \%$ dos tumores analisados (Fig.2).

Uma mutação foi encontrada em um macho, entre 7 e 9 anos, sem raça definida e com o tumor localizado na cabeça. A segunda mutação também foi encontrada em um macho, entre 7 e 9 anos, Boxer e com localização tumoral desconhecida. A terceira mutação foi encontrada em uma fêmea, entre 10 e 12 anos, Pug e com tumor em membro.

A presença da mutação demonstrou independência das variáveis sexo $\left(\chi^{2}=0,25, \mathrm{gl}=1, \mathrm{p}=0,875\right)$, idade $\left(\chi^{2}=2,919\right.$, gl. $=4, p=0,571)$, raça $\left(\chi^{2}=8,407, g l .=10, p=0,589\right)$ e localização $\left(\chi^{2}=7,708, g l .=5, p=0,173\right)$.

Dos três tumores com mutação, dois eram de grau II (tumores com diferenciação intermediária) e um era de grau III (tumores indiferenciados). Na classificação de Kiupel et al. (2011), dois dos tumores com mutação no exon 11 eram de alto grau e um de baixo grau.

A presença da mutação também não demonstrou dependência das análises histopatológicas, nem pelo método de Patnaik et al. $(1984)\left(\chi^{2}=0,675, g l .=2, p=0,713\right)$ e nem pelo método de Kiupel et al. (2011) $\left(\chi^{2}=0,526\right.$, gl. $=1$, $\mathrm{p}=0,468)$. O PCR foi independente da concentração de eosinófilos $\left(\chi^{2}=6,085, \mathrm{gl} .=3, \mathrm{p}=0,108\right)$.

Em relação à imuno-histoquímica, dos três tumores com mutação, dois tinham padrão KIT aberrante (um citoplasmático focal e um citoplasmático difuso) e um tinha padrão KIT perimembranoso. Todos os tumores com mutação no exon 11 eram proliferativos na avaliação do Ki-67 (Quadro 4).

A presença de mutação demonstrou independência do padrão $\operatorname{KIT}\left(\chi^{2}=0,236\right.$, gl. $\left.=2, p=0,889\right)$, mas dependência do resultado encontrado no Ki-67 ( $\chi^{2}=6,640$, gl. $\left.=1, p=0,010\right)$.]

\section{DISCUSSÃO}

Há correlação significativa entre os animais idosos e a classificação de Kiupel et al. (2011). Apenas 31\% dos animais idosos apresentaram o padrão perimembranoso na marcação KIT, considerado o padrão com melhor prognóstico (Webster et al. 2004, Webster et al. 2007). Todos os animais que deram resultado proliferativo na análise do Ki-67 e com mutação genética eram idosos, o que concorda com Kiupel et al. (2005) que associaram os animais idosos a um número maior de mutações. Com isso, é possível associar a idade a prognósticos piores.

A localização tumoral é a variável clínica que está mais relacionada ao prognóstico, sendo a classificação de Kiupel, o padrão KIT e o Ki-67 dependentes da localização. Segundo Govier (2003) e London \& Séguin (2003), a localização inguinal, perineal, prepucial e oral, assim como regiões muco-cutâneas, estão relacionadas a um pior grau histológico. Kiupel et al. (2005) descreveram que os tu- mores na cabeça e no pescoço aumentam o risco do desenvolvimento de metástase. Os dados do presente estudo corroboram a literatura (Webster et al. 2004, Webster et al. 2007), pois os tumores nessas localizações estão rela-

Quadro 4. Distribuição das duas classificações histológicas, marcadores imuno-histoquímicos e análise da PCR

\begin{tabular}{|c|c|c|c|c|c|}
\hline Número & Patnaik & Kiupel & c-KIT & $\mathrm{Ki}-67$ & PCR \\
\hline 1 & II & Baixo & Perimembranoso & - & - \\
\hline 2 & II & Baixo & Perimembranoso & - & - \\
\hline 3 & II & Baixo & Difuso & - & - \\
\hline 4 & II & Baixo & Perimembranoso & - & - \\
\hline 5 & II & Baixo & Focal & - & - \\
\hline 6 & III & Baixo & Focal & Não Proliferativo & - \\
\hline 7 & II & Baixo & Focal & - & - \\
\hline 8 & II & Baixo & Perimembranoso & - & - \\
\hline 9 & II & Baixo & Perimembranoso & - & - \\
\hline 10 & II & Baixo & Perimembranoso & Não Proliferativo & - \\
\hline 11 & II & Baixo & Perimembranoso & - & - \\
\hline 12 & I & Baixo & Perimembranoso & Não Proliferativo & - \\
\hline 13 & III & Alto & Difuso & - & - \\
\hline 14 & II & Baixo & Difuso & - & - \\
\hline 15 & II & Baixo & Perimembranoso & - & - \\
\hline 16 & II & Baixo & Perimembranoso & - & - \\
\hline 17 & II & Baixo & Perimembranoso & - & - \\
\hline 18 & II & Baixo & Perimembranoso & - & - \\
\hline 19 & II & Baixo & Focal & - & - \\
\hline 20 & I & Baixo & Perimembranoso & - & - \\
\hline 21 & II & Alto & Difuso & - & - \\
\hline 22 & II & Baixo & Perimembranoso & - & - \\
\hline 23 & II & Alto & Difuso & - & - \\
\hline 24 & II & Baixo & Perimembranoso & - & - \\
\hline 25 & III & Baixo & Difuso & Não Proliferativo & normal \\
\hline 26 & II & Alto & Difuso & - & normal \\
\hline 27 & II & Baixo & Perimembranoso & Não Proliferativo & normal \\
\hline 28 & II & Baixo & Focal & - & - \\
\hline 29 & II & Alto & Focal & Proliferativo & - \\
\hline 30 & II & Alto & Difuso & - & normal \\
\hline 31 & II & Baixo & Perimembranoso & - & - \\
\hline 32 & II & Baixo & Perimembranoso & - & normal \\
\hline 33 & II & Baixo & Difuso & - & normal \\
\hline 34 & I & Baixo & Perimembranoso & - & - \\
\hline 35 & II & Alto & Focal & - & normal \\
\hline 36 & II & Baixo & Perimembranoso & - & normal \\
\hline 37 & I & Baixo & Focal & Não Proliferativo & normal \\
\hline 38 & II & Baixo & Perimembranoso & Não Proliferativo & normal \\
\hline 39 & II & Alto & Difuso & Não Proliferativo & normal \\
\hline 40 & I & Baixo & Perimembranoso & - & normal \\
\hline 41 & III & Alto & Difuso & Não Proliferativo & normal \\
\hline 42 & II & Alto & Focal & - & normal \\
\hline 43 & III & Alto & Difuso & Não Proliferativo & normal \\
\hline 44 & I & Baixo & Perimembranoso & - & normal \\
\hline 45 & III & Alto & Difuso & - & normal \\
\hline 46 & II & Alto & Perimembranoso & Não Proliferativo & normal \\
\hline 47 & II & Baixo & Perimembranoso & Não Proliferativo & normal \\
\hline 48 & III & Alto & Difuso & Proliferativo & normal \\
\hline 49 & II & Baixo & Perimembranoso & Proliferativo & mutante \\
\hline 50 & II & Alto & Difuso & Proliferativo & normal \\
\hline 51 & III & Alto & Difuso & Proliferativo & mutante \\
\hline 52 & III & Alto & Focal & Não Proliferativo & normal \\
\hline 53 & II & Baixo & Perimembranoso & - & normal \\
\hline 54 & II & Baixo & Difuso & Proliferativo & normal \\
\hline 55 & II & Baixo & Focal & Não Proliferativo & - \\
\hline 56 & II & Baixo & Focal & Não Proliferativo & normal \\
\hline 57 & II & Baixo & Difuso & Proliferativo & normal \\
\hline 58 & III & Alto & Focal & Proliferativo & normal \\
\hline 59 & II & Baixo & Perimembranoso & Não Proliferativo & normal \\
\hline 60 & II & Baixo & Perimembranoso & Não Proliferativo & normal \\
\hline 61 & II & Alto & Focal & Proliferativo & mutante \\
\hline
\end{tabular}


cionados a tumores de alto grau e com localização citoplasmática.

Por outro lado, os mastocitomas nos membros tinham comportamento menos agressivo, pois $80 \%$ deles eram de baixo grau e $65 \%$ tinham padrão KIT perimembranoso, corroborando com Forrest (1997), que relatou que os mastocitomas nos membros tinham comportamento benigno, $\mathrm{e}$ com Oliveira (2008), que classificou a maioria dos mastocitomas no membro como de grau I. Os tumores disseminados apresentavam graus baixos e padrão perimembranoso, o que corrobora com os autores (Thamm et al. 1999, Séguin et al. 2001, Thamm \& Vail 2001) que não os associam a piores prognósticos.

A classificação de Kiupel é independente do sexo e da raça, mas dependente da idade e da localização. De acordo com a análise estatística, os animais mais velhos estão propensos a desenvolverem tumores de alto grau e tumores genitais ou na região de cabeça e no pescoço.

As duas classificações histopatológicas são dependentes uma da outra, com alta significância, assim, para cada grau de Patnaik, deve-se esperar um determinado grau de Kiupel. O maior problema da classificação de Patnaik são os tumores de grau II que, mesmo sendo a grande maioria dos diagnósticos, têm comportamento difícil de prever e com grande variação entre patologistas, o que estimulou a criação da classificação de Kiupel (Kiupel et al. 2011). Pensando nisso, muitos patologistas decidiram usar as duas classificações em seus laudos, até que seja definida aquela com melhores resultados (Sabattini et al. 2015).

0 infiltrado de eosinófilos associado ao tumor é comum em mastocitomas (Simoes et al. 1994, Gross et al. 2005, Oliveira 2008) e estava presente em $90 \%$ dos tumores. Contudo, não foi verificada relação da concentração de eosinófilos e o grau histopatológico. A ausência de relação entre a concentração de eosinófilos e o grau tumoral já foi relatada em literatura (Oliveira 2008). Gross et al. (2005) sugeriram que a eosinofilia diminui à medida que aumenta a anaplasia, porém alguns tumores indiferenciados do presente estudo apresentavam infiltrado intenso de eosinófilos.

Não há relatos em literatura que expliquem a correlação entre a concentração de eosinófilos e a marcação do Ki-67. Porém, nenhum tumor proliferativo teve concentração intensa de eosinófilos, o que pode indicar que quanto mais proliferativo o tumor, menor a quimiotaxia de eosinófilos.

Foi possível verificar associação estatística entre o padrão KIT e a localização. Essa associação não foi descrita em literatura, mas no presente estudo foi possível observar que os tumores em cabeça, pescoço ou genitais estavam associados a padrões KIT aberrantes.

O padrão KIT demonstrou dependência das duas classificações histológicas, com maior significância com a classificação de Kiupel do que a calculada para a classificação de Patnaik, o mesmo ocorreu no estudo de Giantin et al. (2012). 0 alto risco relativo demonstrado indica que tumores de baixo grau estão associados a padrões perimembranosos, enquanto os de alto grau estão associados a padrões citoplasmáticos.

O padrão KIT é considerado um forte fator prognóstico para os mastocitomas caninos, especialmente no que diz respeito à associação entre o padrão citoplasmático, o aumento da proliferação celular, o grau histopatológico (Zemke et al. 2002, Kiupel et al. 2005, Webster et al. 2006a, Giantin et al. 2012) e a um comportamento mais agressivo (Patruno et al. 2014). 0 presente estudo demonstrou forte associação entre o padrão KIT e a classificação histológica.

A proliferação tumoral demonstrou independência do sexo, da raça e da idade, mas dependência da localização. Foi possível observar que os tumores no membro, associados a melhores prognósticos, eram, em sua maioria (67\%), não proliferativos, enquanto os de cabeça e genital, associados a piores prognósticos, eram proliferativos $(83,3 \%)$.

Strefezzi et al. (2010) relataram correlação significativa entre o número de células marcadas pelo Ki-67 e a classificação de Patnaik. No presente estudo, o número de células marcadas pelo Ki-67 não demonstrou relação com nenhuma das classificações histológicas.

A frequência da mutação encontrada no presente estudo foi de 7,7\% similar à encontrada por Zemke et al (2002), mas bem menor do que outras citadas por London et al. (1999) e Jones et al. (2004), de quase 50\%, que pode ser explicada por só terem sido usados animais de grau II e III nos estudos citados.

A duplicação em tandem no exon 11 é a mutação mais frequente em cães (Webster et al. 2006b) e a melhor caracterizada (Jones et al. 2004). Porém, em um estudo mais recente, Amagai et al. (2013) relataram que a duplicação em tandem do domínio justamembrana está presente apenas em uma pequena quantidade de mastocitomas e que, mesmo que estes indivíduos apresentem mais de um tumor, a mutação não estará presente em todos eles. A presença de deleções no exon 11 e mutações em outras localizações já foram relatadas por Zemke et al. (2002) e Webster et al. (2006b).

No presente estudo, não foram encontradas mutações em um grande número de animais. Isso pode ocorrer pela presença de mutação em outros genes do $c$-KIT que não foram investigados (London et al. 1999).

A mutação não demonstrou correlação significativa com nenhuma das variáveis clínicas (sexo, idade, raça e localização). Essa ausência de associação com as variáveis foi descrita por Downing et al. (2002) e Zemke et al. (2002).

Uma das mutações encontradas foi em um cão da raça Boxer, mas este fato não é suficiente para indicar a predisposição genética desses animais, uma vez que foi encontrado o mesmo número de mutações em cães da raça Pug e em um cão sem raça definida.

Não houve correlação estatística significativa entre nenhuma das classificações histopatológicas e a presença de mutação, conforme citado por Downing et al. (2002). Da mesma maneira que Zemke et al. (2002), não foram encontradas mutações em nenhum animal com mastocitoma de grau I e $10 \%$ dos animais com grau II apresentavam mutações.

Pela classificação histopatológica em dois graus, duas mutações eram em animais com tumor de alto grau e uma era em um tumor de baixo grau. A classificação de alto grau é aquela que tem o pior prognóstico (Kiupel et al. 2011), por isso, a maior frequência de mutações nos tumores de alto grau é esperada. Giantin et al. (2012) descreveram a presença de mutação em todos os graus histopatológicos, 
mas a porcentagem de tumores de baixo grau com mutação foi maior do que os tumores de alto grau.

A localização aberrante do KIT já foi citada como relacionada à presença de mutação (London et al. 1999, Webster et al. 2004, Webster et al. 2006a). Webster et al. (2006b) relatam correlação significativa entre a presença de mutação e a mudança na localização do KIT na imuno-histoquímica. Essa dependência não foi verificada no presente estudo.

Um dos animais com a mutação tinha padrão perimembranoso. Segundo Webster et al. (2006a,b), uma explicação seria a aquisição recente da mutação, que ainda não modificou a localização do KIT. Porém, a alteração da localização do KIT pode ser um evento separado da presença da mutação, já que, no presente estudo, dos 33 animais avaliados, 20 tinham padrão citoplasmático. Destes, 18 não apresentavam mutação. 0 mesmo foi verificado por Webster et al. (2006a), que sugerem que a mutação em outros locais ou outros fatores podem estar relacionados à alteração da localização membranosa do KIT. Tanto a presença de mutação ou a localização aberrante do KIT estão associados a prognósticos piores (Webster et al. 2007), mas mesmo tumores sem mutação podem proliferar e ter comportamento maligno (Giantin et al. 2012). Segundo Webster et al. (2006a), a localização aberrante do KIT é mais importante na patogênese do tumor do que a superexpressão do $c$-KIT.

Todos os tumores com mutação eram proliferativos na marcação do Ki-67 e há dependência estatística entre a presença de mutação e a marcação do Ki-67. Isso corrobora com os resultados de Webster et al. (2007), que associam a presença de mutação e a localização aberrante do KIT com a proliferação celular em mastocitomas cutâneos.

0 mastocitoma é um tumor complexo que exige a realização de uma série de exames para prever o comportamento biológico e realizar o tratamento adequado, aumentando a sobrevida e diminuindo o risco de recidivas.

\section{CONCLUSÕES}

Tumores em membros estão relacionados à melhores prognósticos, enquanto tumores de cabeça, pescoço e em região genital estão relacionados a variáveis com piores prognósticos, como os tumores de alto grau, padrões citoplasmáticos de KIT e tumores proliferativos.

Dentre as classificações histopatológicas, a classificação de Kiupel é a que demonstra maior associação com o prognóstico e deve ser preconizada nos diagnósticos do mastocitoma, associadas ao padrão KIT.

\section{REFERÊNCIAS}

Amagai Y., Tanaka A., Matsuda A., Jung K., Oida K., Nishikawa S., Jang H. \& Matsuda H. 2013. Heterogeneity of internal tandem duplications in the c-kit of dogs with multiple mast cell tumours. J. Small Anim. Pract. 54:377-380.

Costa-Casagrande T.A., Elias D.S., Melo S.R. \& Matera J.M. 2008. Estudo retrospectivo do mastocitoma canino no serviço de Cirurgia de pequenos animais, Hospital Veterinário da Faculdade de Medicina Veterinária e Zootecnia da Universidade de São Paulo. Arch. Vet. Sci. 13(3):176-183.

Crow S.E. 1977. Treatment of a mast cell tumor in a dog. Modern Vet. Pract. 58:766-767.

Daleck C.R., De Nardi A.B. \& Rodaski S. 2008. Oncologia em Cães e Gatos. Roca, São Paulo. 612p.
Downing S., Chien M.B., Kass P.H., Moore P.E. \& London C.A. 2002. Prevalence and importance of internal tandem duplications in exons 11 and 12 of c-kit in mast cell tumors of dogs. Am. J. Vet. Res. 63:1718-723.

Forrest L. 1997. Combination cancer treatment: Surgery and radiation therapy. Vet. Med. 92(12):1043-1049.

Fulcher R., Ludwig L., Bergman P., Newman S., Simpson A. \& Patnaik A.K. 2006. Evaluation of a two-centimeter lateral surgical margin for excision of grade I and Grade II cutaneous mast cell tumors in dogs. J. Am. Vet. Med. Assoc. 288(2):210-215.

Furlani J.M., Daleck C.R., Vicenti F.A.M., De Nardi A.B., Pereira G.T., Santana A.E., Eurides D. \& Silva L.A.F. 2008. Mastocitoma canino: estudo retrospectivo. Ciênc. Anim. Bras. 9(1):242-250.

Giantin M., Vascellari M., Morello E.M., Capello K., Vercelli A., Granato A., Lopparelli R.M., Nassuato C., Carminato A., Martano M., Mutinelli F. \& Dacasto M. 2012. c-KIT messenger RNA and protein expression and mutations in canine cutaneous mast cell tumors: correlations with post-surgical prognosis. J. Vet. Diagn. Invest. 24(1):116-126.

Goldschmidt M.H. \& Hendrick M.J. 2002. Tumors of the skin and soft tissues, p.105-109. In: Meuten D.J. (Ed.), Tumors in Domestic Animals. 4th ed. Iowa State Press, Ames.

Govier S.M. 2003. Principles of treatment for mast cell tumors. Clin. Tech. Small Anim. Pract. 18:103-106.

Gross T.L., Ihrke P., Walder E.J. \& Affolter V.K. 2005. Mast cell tumors, p.853-865. In: Ross T.L., Walder E.J. \& Affolter V.K. (Eds), Skin Diseases of the Dog and Cat: clinical and histopathological diagnosis. 2nd ed. Science Ltd, Oxford.

Jones C.L.R., Grahn R.A., Chien M.B., Lyons L.A. \& London C.A. 2004. Detection of c-kit mutations in canine mast cell tumors using fluorescent polyacrylamide gel electrophoresis. J. Vet. Diagn. Invest. 16:95-100.

Kiupel M., Webster J.D., Kaneene J.B., Miller R. \& Yuzbasiyan-Gurkan V. 2004. The use of KIT and tryptase expression patterns as prognostic tools for canine cutaneous mast cell tumors. Vet. Pathol. 41:371-377.

Kiupel M., Webster J.D., Miller R. \& Kaneene J. 2005. Impact of tumour depth, tumor location and multiple synchronous masses on the prognosis of canine cutaneous mast cell tumours. J. Vet. Med. 52:280-286.

Kiupel M., Webster J.D., Bailey K.L., Best S., Delay J., Detrisac C.J., Fitzgerals S.D., Gamble D., Ginn P.E., Goldschimidt M.H., Hendrick M.J., Howerth E.W., Janovitz E.B., Langohr I., Lenz S.D., Lipscomb T.P., Miller M.A., Misdorp W., Moroff S., Mullaney T.P., Neyens I., O'toole D., Ramos-Vara J., Scase T.J., Schulman F.Y., Sledge D., Smedley R.C., Smith K., Stromberg P.C., Valli V.E., Weisbrode S.E., Yager J., Heller J. \& Miller R. 2011. Proposal of a 2-tier histologic grading system for canine cutaneous mast cell tumors to more accurately predict biological behavior. Vet. Pathol. 48(1):147-155.

London C.A. 2009. Tyrosine kinase inhibitors in veterinary medicine. Top. Companion Anim. Med. 24:106-112.

London C.A. \& Séguin B. 2003. Mast cell tumors in the dog. Vet. Clin. North Am., Small anim. Pract. 33:473-489.

London C.A., Kisseberth W.C., Galli S.J., Geissler E.N. \& Helfand S.C. 1996. Expression of stem cell factor receptor (c-kit) by the malignant mast cells from spontaneous canine mast cell tumours. J. Comp. Pathol. 115:399-414.

London C.A., Galli S.J., Yuuki T., Hu Z.Q., Helfand S.C. \& Geissler E.N. 1999. Spontaneous canine mast cell tumors express tandem duplications in the proto-oncogene c-kit. Exp. Hematol. 27:689-697.

Morini M., Bettini G., Preziosi R. \& Mandroli L. 2004. C-kit gene product (CD117) immunoreactivity in canine and feline paraffin sections. J. Histochem. Cytochem. 52(5):705-708.

Oliveira J.M.P. 2008. Aspectos patológicos do mastocitoma cutâneo canino: relação com características epidemiológicas e clínicas e seu valor prognóstico. Tese de Doutorado, Universidade de Trás-os-Montes e Alto Douro, Vila Real, Portugal.

Patnaik A.K., Ehler W.J. \& MacEwen E.G. 1984. Canine cutaneous mast cell tumor: morphologic grading and survival time in 83 dogs. Vet. Pathol, 21:469-474.

Patruno R., Marech I., Zizzo N., Ammendola M., Nardulli P., Gadaleta C., Introna M., Capriuolo G., Rubini R.A., Ribatti D., Gadaleta C.D. \& Ranie- 
ri G. 2014. C-Kit expression, angiogenesis, and grading in canine mast cell tumour: a unique model to study C-Kit driven human malignancies. Biomed. Res. Int. 2014:1-8.

Reguera M., Rabanal R., Puigdemont A. \& Ferrer L. 2000. Canine mast cell tumors express stem cell factor receptor. Am. J. Dermatopathol. 22(1):49-54.

Sabattini S., Scarpa F., Berlato D. \& Bettini G. 2015. Histologic grading of canine mast cell tumor: is 2 better than 3? Vet. Pathol. 52(1):70-73.

Séguin B., Bregazzi V.S., Powers B.E. \& Fettman M.J. 2001. Clinical outcome of dogs with grade-II mast cell tumors treated with surgery alone: 55 cases (1996 -1999). J. Am. Vet. Med. Assoc. 218(7):1120-1123.

Simoes J.P.C., Schoning P. \& Butine M. 1994. Prognosis of canine mast cell tumors: a comparison of three methods. Vet. Pathol. 31:637.

Strefezzi R.F., Kleeb S.R., Xavier J.G. \& Catão-Dias J.L. 2010. Avaliação da proliferação celular como indicador prognóstico para mastocitomas cutâneos caninos. Pesq. Vet. Bras. 30(7):559-565.

Thamm D., Mauldin E. \& Vail D. 1999. Prednisone and vinblastine chemotherapy for canine mast cell tumor: 41 cases (1992-1997). J. Vet. Int. Med. 13:491-497.
Thamm D. \& Vail D.M. 2001. Mast Cell Tumors, p.261-282. In: Withrow S.J. (Ed.), Small Animal Oncology. W.B. Saunders Company, Philadelphia.

Webster J., Kiupel M., Kaneene J., Miller R. \& Yuzbasiyan-Gurkan V. 2004. The use of kit and tryptase expression patterns as prognostic tools for canine mast cell tumors. Vet. Pathol. 41:371-377.

Webster J.D., Kiupel M. \& Yuzbasiyan-Gurkan V. 2006a. Evaluation of the kinase domain of c-KIT in canine cutaneous mast cell tumors. BMC Cancer 1(6):85-92.

Webster J.D., Yuzbasiyan-Gurkan V., Kaneene J.B., Miller R., Resau J.H. \& Kiupel M. 2006b. The role of c-kit in tumorigenesis: evaluation in canine cutaneous mast cell tumors. Neoplasia 8(2):104-111.

Webster J.D., Yuzbasiyan-Gurkan V., Miller R.A., Kaneefe B. \& Kiupel M. 2007. Cellular proliferation in canine cutaneos mast cell tumors: associations with c-KIT and its role in prognostication. Vet. Pathol. 44(3):298-308.

Withrow S.J. \& Vail D.M. 2007. Withrow. MacEwen's Small Animal Clinical Oncology. 4th ed. Saunders Elsevier, St Louis. 846p.

Zemke D., Yamini B. \& Yuzbasiyan-Gurkan V. 2002. Mutations in the juxtamembrane domain of c-KIT are associated with higher grade mast cell tumors in dogs. Vet. Pathol, 39:529-535. 